\title{
Assembly and maintenance of subtidal habitat heterogeneity: synergistic effects of light penetration and sedimentation
}

\author{
Sean D. Connell* \\ Southern Seas Ecology Laboratories, DP418, School of Earth and Environmental Sciences, The University of Adelaide, \\ South Australia 5005, Australia
}

\begin{abstract}
I experimentally separated the positive and negative effects of light penetration and sedimentation on the assembly and maintenance of 3 subtidal habitats whose heterogeneity characterizes much of the world's temperate coastline; encrusting (non-geniculate) coralline algae, articulated (geniculate) coralline algae and filamentous, turf-forming algae. The ability of encrusting corallines to monopolize and retain space without overgrowth depended on the presence of shade (positive effect) if sediment deposition was below that observed on coast characterized by high rates of sedimentation (negative effect). In contrast, the growth and persistence of articulated corallines depended on the absence of shade (negative effect) and high levels of sediment accumulation observed on human-dominated coast (positive effect). The recruitment of filamentous-turfs was facilitated by full light, but was not strongly affected by sedimentation. Instead, filamentous-turfs tolerated heavy sediment accumulation, a factor thought to explain the concomitant increase in spatial dominance of algal-turfs and loss of canopy-forming algae on reefs with heavy sedimentation. Importantly, different habitats will assemble or be maintained to match the environmental conditions in which they are most extensive, demonstrating the key role of physical factors associated with habitat-formers (kelp forests) and human-dominated coast (heavy sedimentation). These results also demonstrate that an appreciation of the integrated roles of physical processes may assist the development of predictive models about the assembly and maintenance of heterogeneity of natural communities, and their potential disruption by humans.
\end{abstract}

KEY WORDS: Algae $\cdot$ Human $\cdot$ Impact $\cdot$ Positive effect $\cdot$ Understorey

\section{INTRODUCTION}

Understanding the processes that maintain habitat heterogeneity is a central theme of community ecology and conservation (Roughgarden \& Diamond 1986). Subtidal habitats are notoriously heterogeneous (Witman \& Dayton 2001), producing patterns of local complexity that are repeated across thousands of kilometres of coast (Irving et al. 2004a). Variation in light intensity has profound consequences for the maintenance of subtidal habitat because the community dominants (e.g. kelp and corals) often rely on photosynthesis that is directly influenced by light intensity.
While many physical properties co-vary with light intensity (e.g. depth), a key, but surprisingly littlestudied, co-variate is sedimentation (Airoldi 2003).

Potential synergies between light intensity and sedimentation are not widely studied in subtidal ecology, but their interaction may explain a considerable amount of natural variation of subtidal habitat. In 'natural' systems, light intensity and sediment accumulation can be lower under canopies (Connell 2003a,b), and interact with surface orientation to maintain invertebrate-dominated assemblages on down-facing surfaces (reduced light and sediment accumulation) whose taxa fail to recruit or survive on up-facing sur- 
faces dominated by algae (enhanced light and sediment accumulation) (Irving \& Connell 2002a). Human activities that release sediment into coastal waters may not only increase sediment deposition (Airoldi 2003), but also reduce light penetration through increased turbidity (Ruffin 1998). The 2 factors may not always be linked, but it is clear that an experimental understanding of the interactive effects of these 2 factors can provide substantial insights into the 'natural' processes that maintain habitat and how this maintenance may be disrupted.

Renewed interest in the maintenance of communities has highlighted the interplay between positive feedbacks, particularly through the presence of habitat-forming organisms and human activity (Bruno \& Bertness 2001). Habitat-formers and humans profoundly affect the physical environment to facilitate or exclude species in the origin of communities. For example, while a physical condition (e.g. shade) can cause 'stress' that suppresses an organism's potential for growth or precludes it from an assemblage (Grime 1977), it may represent a facilitator to other organisms (e.g. shade-tolerant organisms). In this way, heterogeneity of communities has been usefully viewed as the sum of both positive and negative effects (Callaway 1995), but such net effects have rarely been explicitly divided into their positive and negative components (Bruno et al. 2003).

This study assessed the positive and negative effects of light and sedimentation on the assembly and maintenance of subtidal habitats that characterize much of the world's temperate coastline: encrusting (nongeniculate) coralline algae, articulated (geniculate) coralline algae and filamentous, turf-forming algae (Witman \& Dayton 2001, Irving et al. 2004a). Across Australia, these habitats co-vary with the presence and absence of the canopy-forming kelp Ecklonia radiata. On the south coast, encrusting coralline algae monopolize the understorey of $E$. radiata, whereas 2 types of algal-turfs (filamentous turfs comprising tightly packed filamentous algae $<4 \mathrm{~cm}$ in height, and articulated coralline algae) form extensive habitats in the absence of canopy-forming algae (Fowler-Walker \& Connell 2002).

Continuing work has established that encrusting corallines monopolize the understorey because canopy-shade facilitates their growth (Connell 2003b) and sweeping fronds exclude fouling invertebrates by abrading the bottom (Connell 2003a). When forests are experimentally cleared, encrusting corallines immediately reduce their photosynthetic activity and bleach (Irving et al. 2004b), and are then overgrown by epiphytic algae that produce a new system dominated by algal-turfs (Melville \& Connell 2001) that typically trap large amounts of sediment. Indeed, turf-forming algae have a sediment-trapping morphology that enables them to dominate space under heavy sediment deposition (Airoldi 2003), including South Australia's humandominated coast (Gorgula \& Connell 2004). These algae are most extensive in the absence of canopyforming algae (Irving et al. 2004a) on coasts with few benthic grazers (Western and South Australia, FowlerWalker \& Connell 2002, Vanderklift \& Kendrick 2004). While grazers are considered fundamental to shaping the relative covers of encrusting coralline algae and algal-turfs in eastern Australia (Fletcher 1987), and many other parts of the world (Chapman \& Johnson 1990, Shears \& Babcock 2002), their influence in South Australia is negligible relative to effects of canopyforming algae (S. D. Connell unpubl. data).

Taken together, these studies suggest that variation in light intensity and sedimentation could account for a substantial amount of variation in the presence and spatial extent of these habitats. I assessed the model that shade and sediment act in opposite directions to facilitate 1 habitat-type, while simultaneously suppressing an alternate habitat-type. Previous work has assessed the effects of enhanced sedimentation and nutrients in the absence of canopies (positive effect on filamentous turfs, Gorgula \& Connell 2004), and the combined effects of canopy-mediated shade and sedimentation (positive effect on encrusting coralline algae, Connell 2003b); yet, we still lack knowledge on the interactive effects of sediment deposition and light intensity during the assembly and maintenance of habitat heterogeneity.

I experimentally tested the hypotheses that (1) shade not only facilitates encrusting coralline algae, but also suppresses both types of turf-forming algae, (2) full light facilitates both types of turf-forming algae, particularly with the heavy levels of sediment deposition experienced on human-dominated coast. For this assessment, it was useful to distinguish between the mechanisms of positive-feedback that sustain heterogeneity of habitat (i.e. the problem of maintenance) from the mechanisms that govern the assembly of heterogeneity (i.e. the problem of early divergence). In these experiments, I therefore compared the effects of shade and sedimentation on the assembly of habitat with the ability of these factors to maintain them.

\section{MATERIALS AND METHODS}

Study site. Experiments were performed on a boulder reef (3 to $5 \mathrm{~m}$ deep) in Abalone Cove, West Island, South Australia (Fig. 1; $35^{\circ} 36^{\prime} \mathrm{S}, 138^{\circ} 35^{\prime} \mathrm{E}$ ). Boulders are granitic, approximately $300 \mathrm{~mm}$ across by $80 \mathrm{~mm}$ deep and covered by sediments of fine sand in the absence of stipate canopy-forming algae (Shepherd \& 
Womersley 1970). Boulders support extensive monospecific stands of kelp Ecklonia radiata and sparse or patchy stands of fucoids (particularly, Cystophora moniliformis and $C$. subfarcinata). E. radiata grow to about $800 \mathrm{~mm}$ in height, but were mostly $\sim 630 \mathrm{~mm}$ high at the time of study. The 3 habitats studied (encrusting and articulated coralline algae, and filamentous turfs) and their association with canopyforming algae at West Island (Melville \& Connell 2001) is representative of much of Australia's south coast (Fowler-Walker \& Connell 2002). Detailed descriptions of the physical environment at West Island and its association with these algae are provided in Shepherd \& Womersley (1970).

The experimental design. The effects of light and sedimentation were tested in a fully fixed, factorial design $(3$ sediment $\times 4$ shade treatments; $\mathrm{n}=5$ replicates per treatment). This design provided for 60 replicate units that were deployed for $338 \mathrm{~d}$ (December 1999 to November 2000). Light was manipulated in 4 different treatments: (1) heavy shade, (2) partial shade (equivalent to canopy-mediated shade), (3) no shade and (4) a procedural control (see Fig 2. in Connell 2003b). Sedimentation was manipulated so the deposition of sediments was enhanced (Addition), unmanipulated (Natural) and reduced (Removed). These treatments were randomly assigned to 60 plots from which I removed monspecific stands of Ecklonia radiata to create plots large enough $(1500 \times 1500 \mathrm{~mm})$ to prevent edge effects (i.e. of the kelp) on treatments $(600 \times$ $600 \mathrm{~mm}$, see 'Manipulation and quantification of shade'). Within each treatment, 3 types of habitat (see 'Experimental surfaces' below) growing on boulders

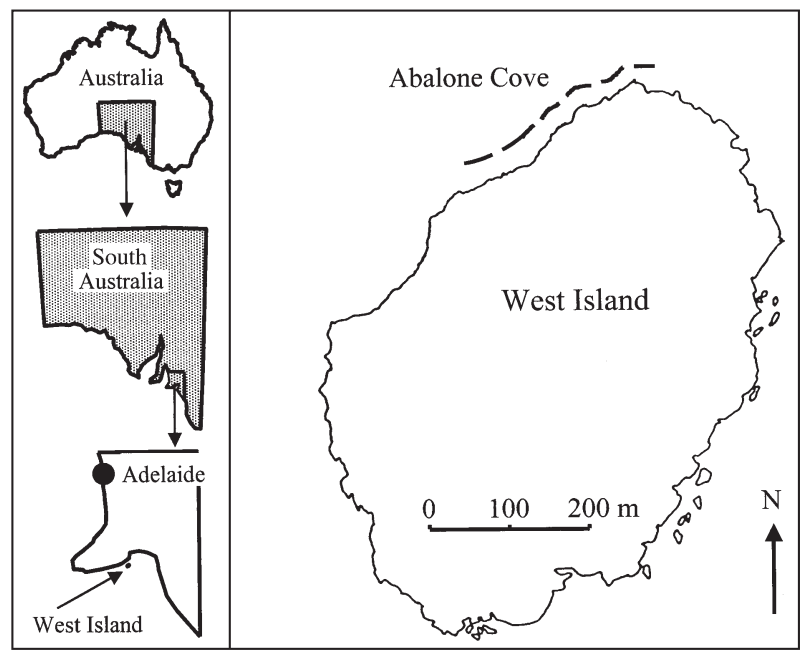

Fig. 1. Map showing location of West Island in South Australia and extent of subtidal rock (dashed line) on which experiments were constructed (Abalone Cove)
( $150 \mathrm{~mm}$ across) were placed flush with the surrounding boulders. Percentage cover of algae on these boulders was estimated approximately every 3 mo for almost $1 \mathrm{yr}$ using the point interception method comprising 25 regularly spaced points within a $100 \times$ $100 \mathrm{~mm}$ quadrat.

The experimental surfaces. Three types of boulder ( $150 \mathrm{~mm}$ across) were transplanted to each treatment and placed flush with the surrounding boulders to test the effect of treatments on the assembly and maintenance of differing habitat-types. The assembly of habitat was observed on virgin habitat (unoccupied space), which consisted of entirely bare, sun-bleached boulders sourced from above the intertidal zone. The maintenance of habitat was tested on boulders that represented the dominant natural type in the presence and absence of canopies. The maintenance of encrusting coralline algae was tested on boulders whose upper surface was $100 \%$ covered by encrusting corallines algae and located from within forests of Ecklonia radiata. The algae that formed encrusting coralline habitat were primarily Mesophyllum incisum, $M$. macroblastum and Lithophyllum johansenii red algae (Rhodophyceae). The maintenance of articulated coralline algae was tested on boulders whose upper surface was primarily covered by articulated corallines ( $>60 \%$ cover: mean $\pm \mathrm{SE}=79 \pm 1 \%$ ) and located from reefs without canopy-forming algae. The algae that formed articulated coralline habitat were primarily Haliptilon roseum, Amphiroa anceps, Metagoniolithon radiatum, Corallina sp. and Jania sp. (Rhodophyceae).

Manipulation and quantification of shade. Heavy shade was created by bolting $5 \mathrm{~mm}$ thick black plastic $(600 \times 600 \mathrm{~mm}) 300 \mathrm{~mm}$ above the substratum with steel rods ( $5 \mathrm{~mm}$ thick) at each corner. Partial shade and procedural controls were of the same construction but a translucent cloth (Coolaroo ${ }^{\circledR} 50 \%$ shade cloth) was tied underneath clear Mylor ${ }^{\circledR}$ plastic to create partial shade (equivalent to under canopies of kelp, Connell 2003b) and only clear Mylor ${ }^{\circledR}$ plastic was used for procedural controls. Mylor ${ }^{\circledR}$ plastic (Acrylite OP-U) was used because it allows the maximum penetration of a broad spectrum of UV light, unlike clear plastic. Acrylite OP-U has $>90 \%$ transmittance at $\sim 400$ to $600 \mathrm{~nm}$ (similar to quartz crystal), $86 \%$ transmittance at $320 \mathrm{~nm}$ and $\sim 70 \%$ at $280 \mathrm{~nm}$, as determined by a mass-spectrometer. Treatments of no shade consisted of open plots of rock bottom with no shade structures and no kelp. Comparison of procedural controls with open plots (no shade) was intended to indicate the presence of artefacts associated with the structure.

Treatments provided 3 levels of light intensity, in which partial shade was equivalent to shade under moderate densities of kelp ( $\sim$ plants $\mathrm{mm}^{-2}$ ) (heavy shade $<$ partial shade $=$ kelp $<$ open $=$ control $)$ on each 
of 4 occasions sampled at 3 mo intervals (see Connell $2003 b)$. These observations were based on relative differences in light intensity (log[lumens $\mathrm{m}^{-2}$ ]) quantified simultaneously ( $\mathrm{n}=3$ replicate readings for each of 5 treatments) with Hobo light meters. It is important to qualify that lumens only provide an index of irradiance and not an absolute measure of wavelengths of light used by plants. In the current study, however, Hobos enabled a cost-effective test of whether distinct intensities of light were achieved by the treatments. The ability to cheaply quantify light among all treatments simultaneously (with replication) avoided temporal confounding (e.g. variable cloud cover) associated with the use of 1 or $2 \mathrm{Li}$-Cor meters. This approach may provide information about the effectiveness of treatments, but does not provide a standard measure familiar and useful to phycologists. My current tests on the physiological effects of light (Irving et al. 2004b) necessarily focus on absolute wavelengths of light and require a Li-Cor meter for PAR (400 to $700 \mathrm{~nm}$ : quantified as $\mu \mathrm{E} \mathrm{m}^{-2} \mathrm{~s}^{-1}$ or $\mu \mathrm{mol} \mathrm{m} \mathrm{m}^{-2} \mathrm{~s}^{-1}$ ) and RAMSES Radiometer for ultraviolet radiation (UVB: 280 to $320 \mathrm{~nm}$; UVA: 320 to $400 \mathrm{~nm}$ ).

Manipulation and quantification of sedimentation. Sediment accumulation and removal was manipulated on the same visits used to maintain treatments of shade (every $~ 18 \mathrm{~d}$ ). Enhanced accumulation was achieved by adding sediment collected from the boulder reef (39 g wet wt per experimental boulder; equivalent to $29 \mathrm{~g}$ dry wt). Sediments were added as fine 'rain' (Airoldi \& Virgilio 1998) to boulders ( 150 mm across) so that sediment deposition was enhanced by $\sim 72 \mathrm{~g}$ $\mathrm{m}^{-2} \mathrm{~d}^{-1}$ dry wt over $18 \mathrm{~d}$, equivalent to $\sim 1290 \mathrm{~g} \mathrm{~m}^{-2}$ on the day of application ( 1 to $2 \mathrm{~mm}$ depth of sediment). This level of enhancement is within the natural range of sediment deposition observed on metropolitan coasts of South Australia (80 to $470 \mathrm{~g} \mathrm{~m}^{-2} \mathrm{~d}^{-1}$ dry wt; T. J. Greig unpubl. data) and its main harbour (323 to $2033 \mathrm{~g} \mathrm{~m}^{-2} \mathrm{~d}^{-1}$ dry $\mathrm{wt}_{\text {; }}$ Irving \& Connell 2002a) where Ecklonia radiata occurs. Sedimentation was reduced by gently fanning water across boulders to re-suspend the sediment away from the treatments (e.g. Irving \& Connell 2002b), so that no visible sediment remained. The application of these treatments took $\sim 5 \mathrm{~s}$ per boulder. Both types of turf-forming habitats appeared to retain sediment added to treatments assessing maintenance (already colonised) and assembly (becoming colonised) of algal-turfs. Sediment was not retained on boulders already colonised or becoming colonised by encrusting corallines.

Test of artefacts of water flow and sedimentation. Procedural controls do not always provide adequate tests of artefacts, particularly where experiments involve the addition of novel structures to habitat. One of the simplest ways to increase the interpretability of such experiments is to augment controls with direct tests of known or suspected artefacts (Connell 1997). I tested whether the experimental treatments modified rates of sediment deposition and water flow before, during and after mid-austral winter: April, June and August. Sediment traps made from cylindrical polypropylene $(170 \mathrm{~mm}$ high $\times 50 \mathrm{~mm}$ diameter: aspect ratio $>3$ as recommended by Hakanson et al. 1989) were used to collect sediments. One sediment trap was placed at the center of each treatment, so that the opening was slightly raised above the surrounding boulders. The traps were deployed for periods of $\sim 14 \mathrm{~d}$. In the laboratory, each sample was first filtered through $200 \mathrm{~mm}$ mesh (coarse fraction), then through pre-weighed (dried at $70^{\circ} \mathrm{C}$ ) Whatman GF/B $1 \mathrm{~mm}$ filter paper (fine fraction). Both fractions were weighed after reaching a constant weight (dried at $70^{\circ} \mathrm{C}$ ). Plaster cod cards (Jokiel \& Morrissey 1993) were used to test whether relative rates of water flow differed among the treatments. Clods were made from plaster of Paris ( $5 \mathrm{~mm}$ high $\times 5 \mathrm{~mm}$ diameter) and glued to concrete-fibre cards $(70 \times 70 \mathrm{~mm})$ with holes drilled in their corners for attachment. They were weighed after drying at $70^{\circ} \mathrm{C}$ to a constant weight, attached near the middle of the experimental units, left in situ for 24 to $28 \mathrm{~h}(\sim 20 \%$ weight loss $)$ and then dried to a constant weight (at $70^{\circ} \mathrm{C}$ ) before re-weighing.

Statistical treatment of the data. Analyses were performed using ANOVA (Underwood 1997), in which treatments (shade and sediment) were crossed and treated as fixed. 'Time' was treated as random, given that times of sampling represented a random subset of possible times around the austral winter. Homogeneity of variances was judged by Cochran's $C$-test ( $p>0.05$ ) and data were transformed where necessary.

\section{RESULTS}

\section{Assembly of heterogenous habitat}

Heterogeneity of habitat originated through an interactive combination of sediment deposition and shade (Table 1). To assist visual interpretation, the factor showing the largest effect is plotted against time (Fig. 2, left), but the final effect is plotted against all treatments (Fig. 2, right). It is noteworthy that the response only manifested itself after $\sim 100 \mathrm{~d}$, which indicates the minium duration of such experiments.

The percentage cover of encrusting coralline algae was greater under partial and heavy shade when rates of sedimentation were natural or reduced, but shade had a substantially smaller effect when the rate of sediment deposition was enhanced (Fig. 2a, Table 1a: SNK tests). The negative effects of enhanced sedimen- 
Table 1. ANOVA testing the development of algae (percentage cover) on unoccupied space among treatments of shade (heavy, partial, none, procedural control) and sedimentation (addition, natural, removed). NS: $\mathrm{p}>0.05 ;{ }^{*} \mathrm{p}<0.05 ;{ }^{* *} \mathrm{p}<0.01 ;{ }^{* * *} \mathrm{p}<0.001$. To meet assumption of homogeneity, transformations were (b) arc-sine (Cochran's $C$-test, $p>0.05)$ and (c) square root ( $x+1$ ) (Cochran's $C$-test, p > 0.05)

\begin{tabular}{|c|c|c|c|c|c|c|c|c|c|c|}
\hline \multirow[t]{2}{*}{ Source } & \multirow[t]{2}{*}{ df } & \multicolumn{3}{|c|}{ (a) Encrusting corallines } & \multicolumn{3}{|c|}{ (b) Articulated corallines } & \multicolumn{3}{|c|}{ (c) Filamentous turfs } \\
\hline & & MS & $F$ & $\mathrm{p}$ & MS & $F$ & $\mathrm{p}$ & MS & $F$ & $\mathrm{p}$ \\
\hline Shade (Sh) & 3 & 7917.66 & 68.46 & $* * *$ & 692.84 & 23.47 & $* * *$ & 96.59 & 70.89 & $* * *$ \\
\hline Sediment (Sed) & 2 & 1296.52 & 11.21 & ${ }^{* * *}$ & 210.03 & 7.11 & $* *$ & 1.11 & 0.81 & NS \\
\hline $\mathrm{Sh} \times \mathrm{Sed}$ & 6 & 561.23 & 4.85 & $* * *$ & 86.49 & 2.93 & * & 3.39 & 2.49 & $*$ \\
\hline Residual & 48 & 115.65 & & & 29.52 & & & 1.36 & & \\
\hline
\end{tabular}

(a) Encrusting coralline algae

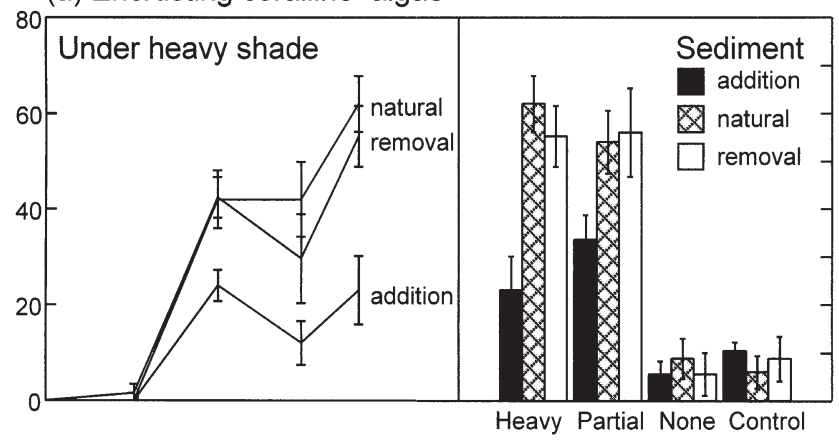

(b) Articulated coralline algae

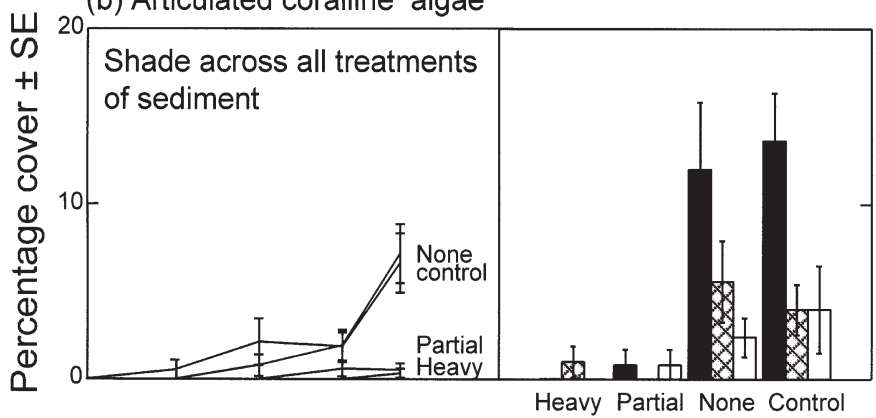

(c) Turfing algae

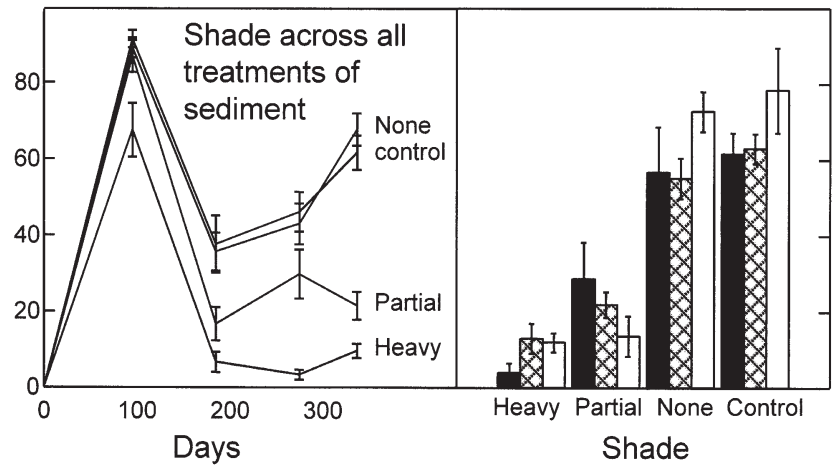

Fig. 2. Effect of shade and sedimentation on the assembly of habitat-type. Line graphs (left) plot the greatest biological effect through time and bar graphs (right) show the final effect of all treatments. Plots through time show (a) the effect of sedimentation within the treatment of heavy shade, (b) and (c) the effect of shade across all levels of sedimentation tation only occurred under shaded treatments (SNK: add $<$ reduce $=$ natural) and not in unshaded treatments (SNK: add $=$ reduce $=$ natural). Mesophyllum incisum and Lithophyllum johansenii primarily contributed to this habitat. Sparse covers of other encrusting red algae were observed (namely, Hildenbrandia spp.), but occurred in insufficient abundance to warrant analysis.

Articulated coralline algae were facilitated by a combination of full light and enhanced sedimentation. The percentage cover of articulated coralline algae was sparsest under lower levels of light and sedimentation (Fig. 2b, Table 1b). Enhanced sedimentation had a positive effect on percentage cover within treatments of no shade and procedural controls (SNK: add > natural = removal), but no effect under partial and heavy shade $($ SNK: add $=$ natural $=$ removal $)$. Full light (no shade and procedural control) only created greater percentage cover (SNK: no shade = procedural control $>$ partial shade = heavy shade) in treatments of high sedimentation (addition and natural), and not when sediments were removed (SNK: no shade $=$ procedural control $=$ partial shade $=$ heavy shade). Amphiroa anceps and Corallina sp. primarily contributed to this habitat.

The percentage cover of filamentous turfing-algae was primarily constrained by shade, and this effect was greatest when shade was heavy and sedimentation was enhanced (Fig. 2c, Table 1c). Full light caused the most extensive cover of filamentous turfs under natural and reduced sedimentation $(\mathrm{SNK}$ : no shade = procedural control $>$ partial shade = heavy shade) and the negative effect of heavy shade was intensified under enhanced rates of sedimentation (SNK: no shade = procedural control $>$ partial shade $>$ heavy shade). Sediment did not have a clear effect on turfs under the experimental regime of sediment manipulation (every $\sim 18 \mathrm{~d}$ ), but addition of sediments had strong positive effects on a similar assemblage at the same location when manipulated more frequently (every day to every week, Gorgula \& Connell 2004). The alga that formed filamentous turfs primarily comprised Feldma- 
$\begin{array}{ll}\text { (a) Encrusting coralline algae } & \text { (b) Articulated coralline algae }\end{array}$

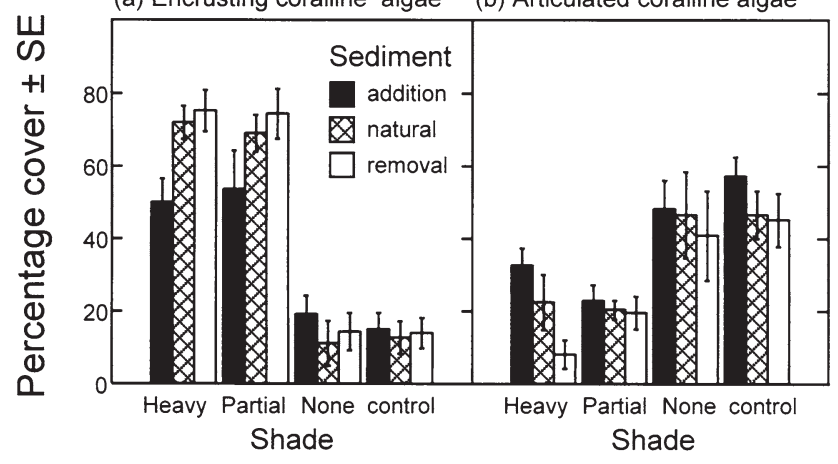

Fig. 3. Effect of shade and sedimentation on the maintenance of (a) encrusting coralline algae and (b) articulated coralline algae

nia sp. (Phaeophyceae), and sparser covers of green algae (Chlorophyceae: Caulerpa fastigata, C. obscura, Cladophora spp., Ulva spp.), brown algae (Phaeophyceae: Ectocarpus sp., Feldmania sp.) and red algae (Rhodophyceae: Ceramium spp., Gelidium spp.). The species of Caulerpa and Ulva observed were juvenile and short forms, which comprised part of the tightly packed filaments of algae that were generally less than 1 to $2 \mathrm{~cm}$ in height.

\section{Maintenance of heterogeneity of habitat}

The percentage cover of encrusting coralline algae (free of overgrowth) was best maintained by a combination of low light (partial and heavy shade) and low sediment accumulation (natural and reduced sedimentation) (Fig. 3a, Table 2a). Shade facilitated cover across all regimes of sedimentation (SNK: heavy $=$ partial $>$ open $=$ procedural control). Enhanced sedimentation, however, reduced the magnitude of this effect under partial and heavy shade (SNK: add $<$ reduce = natural), but not under full light experienced in open plots and controls (SNK: add $=$ reduce $=$ natural). It is noteworthy that there was no difference in percentage covers among treatments of sediment under canopy-equivalent shade (Fig. 3a) and dense canopies ( $>6$ plants $\mathrm{m}^{-2}$ ) of monospecific Ecklonia radiata $(78 \% \pm$ 10.2 $\mathrm{SE}, \mathrm{n}=5$; ANOVA: $F_{3,16}, \mathrm{p}>$ 0.05). This equivalence not only suggests that the decline in cover across all treatments was natural, but also reinforces the prime contribution of canopy-mediated shade to the maintenance of habitat under E. radiata (Connell 2003b).

In contrast to encrusting coralline algae, the percentage cover of articu- lated coralline algae was best maintained by high light (open plots and procedural controls) and enhanced sedimentation (Fig. 3b, Table 2b). Shade, whether partial or heavy, negatively affected persistence (SNK: no shade $=$ procedural control $>$ partial shade $=$ heavy shade). Enhancement of sediment deposition positively affected percentage cover relative to the removal of sediments (SNK: addition > removal), but the effect of enhancing or reducing sedimentation was not detected (SNK: natural = removal, natural $=$ addition). The cause of overall decline in percentage cover of articulated coralline algae (originally $>60 \%$ ) over the duration of the experiment (338 d) is unknown. These changes do not appear to represent artefacts of translocation of boulders (see Melville \& Connell 2001 for comprehensive tests of such artefacts over $\sim 70 \mathrm{~d}$ ).

\section{Test of artefacts of water flow and sedimentation}

Differences in sediment deposition and dissolution of clod cards were detected through time, but not among treatments of shade and sediment. The following analyses (3-way, fully-crossed ANOVA) treated 'Time' as random, and both 'Shade' and 'Sediment' as fixed factors (Cochran's $C$-tests were $\mathrm{p}<0.05$ and sediments were $\log x+1$ transformed). Rates of deposition of coarse sediments differed among months $\left(F_{2,144}, \mathrm{p}<\right.$ 0.001, SNK: April > August $>$ June), but not among treatments of shade $\left(F_{3,6}, \mathrm{p}>0.05\right)$, sedimentation $\left(F_{2,4}, \mathrm{p}>0.05\right)$, or any of their interactions. Deposition of fine sediments differed among months in accordance with coarse sediments (see sentence above), and while a Time $\times$ Sediment interaction $\left(F_{4,144}, \mathrm{p}<0.01\right)$ indicated differences among treatments of shade in August, SNK tests were unable to resolve which treatments differed in this month. Rates of dissolution of plaster clod cards differed among months $\left(F_{2,144}, \mathrm{p}<\right.$ 0.001, $\mathrm{SNK}_{\text {; }}$ August $>$ April $>$ June), but not among treatments of shade $\left(F_{3,6}, \mathrm{p}>0.05\right)$, sedimentation $\left(F_{2,4}, \mathrm{p}>0.05\right)$, or any of their interactions.

Table 2. ANOVA testing the persistence of monopolized space (percentage cover) by alternative habitat-types among treatments of shade (heavy, partial, none, procedural control) and sedimentation (addition, natural, removed). Transformation (b) arc-sine was needed to meet assumption of homogeneity (Cochran's $C$-test, $\mathrm{p}>0.05$ )

\begin{tabular}{|c|c|c|c|c|c|c|c|}
\hline \multirow[t]{2}{*}{ Treatment } & \multirow[t]{2}{*}{ df } & \multicolumn{3}{|c|}{ (a) Encrusting corallines } & \multicolumn{3}{|c|}{ (b) Articulated corallines } \\
\hline & & MS & $F$ & $\mathrm{p}$ & MS & $F$ & $\mathrm{p}$ \\
\hline Shade (Sh) & 3 & 13143.87 & 95.18 & $* * *$ & 1550.79 & 16.64 & $* * *$ \\
\hline Sediment (Sed) & 2 & 526.02 & 3.81 & * & 390.25 & 4.19 & * \\
\hline Sh $\times$ Sed & 6 & 361.55 & 2.62 & * & 98.93 & 1.06 & NS \\
\hline Residual & 48 & 138.10 & & & 93.19 & & \\
\hline
\end{tabular}




\section{DISCUSSION}

These experiments highlight the capacity for physical conditions to impose strong synergistic effects that facilitate the assembly and maintenance of subtidal habitat. Such synergies between physical factors have been recognised (Irving \& Connell 2002a), but their net effects have rarely been dissected into their negative and positive components (but see Bertness et al. 1999). The ability of encrusting corallines to monopolize and retain space without overgrowth depended on the presence of shade (positive effect) if sediment deposition was below that of human-dominated coast (negative effect). In contrast, the growth and persistence of articulated corallines depended on the absence of shade (negative effect) and high levels of sediment accumulation found on human-dominated coast (positive effect). The recruitment of filamentousturfs was facilitated by full light, but was not strongly affected by sedimentation. Instead, filamentous-turfs tolerated heavy sediment accumulation, a factor thought to explain the concomitant increase in spatial dominance of algal-turfs and loss of canopy-forming algae on reefs with heavy sedimentation (Airoldi 2003).

A mechanistic understanding of such positive and negative effects and their amalgams not only provides a more causative account of plant interactions (Callaway \& Walker 1997), but may also account for other ecological patterns affected by a similar suite of processes. The described synergistic effects of light and sedimentation are consistent with positive feedback mechanisms associated with the presence of canopyforming algae (low light; Connell 2003b) and absence of canopy-forming algae (intense light and heavy sedimentation). Whereas algal-turfs incorporate sediment into their structure (Airoldi 2003) and appear to inhibit the recruitment of canopy-forming algae (Devinny \& Volse 1978, Kennelly 1987c), kelps generally prevent the accumulation of sediment and turfs under their canopy (Edwards 1998, Melville \& Connell 2001, Connell 2003b). Natural disturbances to kelp forests (e.g. storms; Kennelly 1987a,b) can create sufficiently large clearances (i.e. past a critical size; Wernberg-Møller 2002), that enable habitat to switch to one monopolized by filamentous-turfs (Kennelly \& Underwood 1993, Melville \& Connell 2001). The present study suggests that light penetration and deposition of sediments are crucial aspects of the physical environment which not only maintain differences in habitat, but can also give rise to early divergence during succession.

It is clear that an experimental understanding of light penetration and sedimentation can also provide substantial insights into processes that may disrupt the natural maintenance of subtidal habitat. Increasing sedimentation and turbidity (Ruffin 1998, Airoldi 2003) are among a broad spectrum of land- and ocean-based activities, coupled with continued growth of the human population and migration to coastal areas, that is driving unprecedented and complex changes in the water chemistry (Boesch et al. 2001) and ecology of marine habitats (Vitousek et al. 1997, Jackson 2001). Enhanced coastal sedimentation may play a key role in such changes to habitat on human-dominated coast (Airoldi 2003). For example, large expanses of Ecklonia radiata forests were lost from South Australia's metropolitan coast following a massive dredging event (November 1997, Cheshire et al. 1999). Today, these forests remain largely absent and this coast now supports extensive tracts of filamentous-turfs that are sustained by enhanced coastal sedimentation and nutrification (Gorgula \& Connell 2004). These changes in habitat appear intergenerational and perhaps permanent. It is likely that $E$. radiata forests have completely turned over since the pulse disturbance (rate of annual mortality of adults $>60 \%$, Hatcher et al. 1987) and the average age of surviving adults ( 2 to $4 \mathrm{yr}$, Larkum 1986).

Most systems exposed to some gradual change (e.g. increasing sediment loading and turbidity) are thought to respond in a gradual way. Of key concern is the increasing frequency with which smooth change has been interrupted by sudden drastic switches to a contrasting state (Scheffer et al. 2001). The theory of 'alternate stable states' provides a framework for understanding this phenomenon, an idea that emerged from work on theoretical models about abrupt switches to contrasting states (Holling 1973, May 1977). Switches in species dominance are predicted to occur after pulse events (e.g. dredging) that change environmental conditions (e.g. light and sedimentation), which in turn starts a positive feedback mechanism resulting in a switch (Petraitis \& Dudgeon 2004a). These ideas are yet to be tested in subtidal kelp, but it is possible that critical thresholds of light and sediment exist (as related to size of clearings of kelp and human activity), and crossing them produces a switch (kelp versus alternate state of habitat). Whether such switches are indeed scale-dependent, and the results intergenerational, is not known in subtidal kelp. While it is possible that Ecklonia radiata forests and algal-turfs represent alternative stable states, evidence for this theory is notoriously difficult to provide (Peterson 1984) and controversial (Bertness et al. 2004, Petraitis \& Dudgeon 2004 b), but could change the way we view the origin and maintenance of these habitats.

In conclusion, it is clear that light penetration and sedimentation combine to place strong local constraints on the assembly and maintenance of particular types of habitat. Heterogeneity of habitat is often asso- 
ciated with the presence and absence of habitat-forming species (Wilson \& Agnew 1992), and homogeneity of habitat by human modification of the environment (Tilman \& Lehman 2001). An appreciation of the integrated roles of physical processes that act in negative and positive ways may assist the development of predictive models about the assembly and maintenance of heterogeneity of natural communities, and their potential disruption by humans. I have shown that by exposing different habitat-types to a set of physical conditions associated with habitat-formers and human-dominated coast, different habitats will assemble or be maintained to match the environmental conditions in which they are most extensive. Such feedback mechanisms (synergies of light penetration and sedimentation) may not only underlie the maintenance of habitat heterogeneity, but may also be key to the processes that operate at the origin and early divergence of different habitats.

Acknowledgements. This manuscript was improved by the comments of L. Airoldi, B. Gillanders and T. Minchinton. Discussions with P. Petraitis about the theory of alternative community states helped clarify my understanding of the origin and maintenance of habitat heterogeneity in this system. Three reviewers provided clear and insightful comments that improved this manuscript and my view of subtidal ecology. Many hundreds of hours of competent diving assistance were provided by B. Gillanders, M. Fowler-Walker and A. Irving. This research was financed by an Australian Research Council grant.

\section{LITERATURE CITED}

Airoldi L (2003) The effects of sedimentation on rocky coast assemblages. Oceanogr Mar Biol Annu Rev 41:161-236

Airoldi L, Virgilio M (1998) Responses of turf-forming algae to spatial variations in the deposition of sediments. Mar Ecol Prog Ser 165:271-282

Bertness MD, Leonard GH, Levine J, Schmidt P, Ingraham A (1999) Testing the relative contribution of positive and negative interactions in rocky intertidal communities. Ecology 80:2711-2726

Bertness MD, Trussell GC, Ewanchuk PJ, Silliman BR (2004) Do alternate stable community states exist in the Gulf of Maine rocky intertidal zone? Reply. Ecology 85:1165-1167

Boesch DF, Burroughs RH, Baker JE, Mason RP, Rowe CL, Siefert RL (2001) Marine pollution in the United States. Pew Oceans Commission, Arlington, VA

Bruno J, Bertness M (2001) Habitat modification and facilitation in benthic marine communities. In: Bertness $M$, Gaines S, Hay M (eds) Marine community ecology. Sinauer Associates, Sutherland, MA, p 201-220

Bruno J, Stachowicz J, Bertness MD (2003) Inclusion of facilitation into ecological theory. Trends Ecol Evol 18:119-125

Callaway RM (1995) Positive interactions among plants. Bot Rev 61:306-349

Callaway RM, Walker LR (1997) Competition and facilitation: a synthetic approach to interactions in plant communities. Ecology 78:1958-1965

Chapman ARO, Johnson CR (1990) Disturbance and organi- zation of macroalgal assemblages in the Northwest Atlantic. Hydrobiologia 192:77-121

Cheshire AC, Miller DJ, Stewart R (1999) Effect of dispersed sediment plumes from beach and sand replenishment dredging on recruitment of phaeophycean algae to rocky reefs in Gulf St. Vincent, South Australia: a report to the Environmental Protection Authority of South Australia. Department of Environmental Biology, University of Adelaide

Connell SD (1997) Exclusion of predatory fish on a coral reef: the anticipation, pre-emption and evaluation of some caging artefacts. J Exp Mar Biol Ecol 213:181-198

Connell SD (2003a) Negative effects overpower the positive of kelp to exclude invertebrates from the understorey community. Oecologia 137:97-103

Connell SD (2003b) The monopolization of understorey habitat by subtidal encrusting coralline algae: a test of the combined effects of canopy-mediated light and sedimentation. Mar Biol 142:1065-1071

Devinny JS, Volse LA (1978) Effects of sediments on the development of Macrocystis pyrifera gametophytes. Mar Biol 48:343-348

Edwards MS (1998) Effects of long-term kelp canopy exclusion on the abundance of the annual alga Desmarestia ligulata (Light F). J Exp Mar Biol Ecol 228:309-326

Fletcher WJ (1987) Interactions among subtidal Australian sea urchins, gastropods and algae: effects of experimental removals. Ecol Monogr 57:89-109

Fowler-Walker MJ, Connell SD (2002) Opposing states of subtidal habitat across temperate Australia: consistency and predictability in kelp canopy-understorey associations. Mar Ecol Prog Ser 240:49-56

Gorgula SK, Connell SD (2004) Expansive covers of turf-forming algae on human-dominated coast: the relative effects of increasing nutrient and sediment loads. Mar Biol 145: 613-619

Grime JP (1977) Evidence for the existence of 3 primary strategies in plants and its relevance to ecological and evolutionary theory. Am Nat 111:1169-1194

Hakanson L, Floderus S, Wallin M (1989) Sediment trap assemblages - a methodological description. Hydrobiologia 176/177:481-490

Hatcher BG, Kirkman H, Wood WF (1987) Growth of the kelp Ecklonia radiata near the northern limit of its range in Western Australia. Mar Biol 95:63-72

Holling CS (1973) Resilience and stability of ecological systems. Annu Rev Ecol Syst 4:1-23

Irving AD, Connell SD (2002a) Sedimentation and light penetration interact to maintain heterogeneity of subtidal habitats: algal vs invertebrate dominated assemblages. Mar Ecol Prog Ser 245:83-91

Irving AD, Connell SD (2002b) Interactive effects of sedimentation and microtopography on the abundance of subtidal turfing algae. Phycologia 41:517-522

Irving AD, Connell SD, Gillanders BM (2004a) Local complexity in patterns of canopy-benthos associations produce regional patterns across temperate Australasia. Mar Biol 144:361-368

Irving AD, Connell SD, Elsdon TS (2004b) Effects of kelp canopies on bleaching and photosynthetic activity on encrusting coralline algae. J Exp Mar Biol Ecol 310:1-12

Jackson BC (2001) What was natural in the coastal oceans? Proc Natl Acad Sci USA 98:5411-5418

Jokiel PL, Morrissey JI (1993) Water motion on coral reefs: evaluation of the 'clod card' technique. Mar Ecol Prog Ser 93:175-181

Kennelly SJ (1987a) Physical disturbances in an Australian 
kelp community. II. Effects on understorey species due to differences in kelp cover. Mar Ecol Prog Ser 40:155-165

Kennelly SJ (1987b) Physical disturbances in an Australian kelp community. I. Temporal effects. Mar Ecol Prog Ser 40: 145-153

Kennelly SJ (1987c) Inhibition of kelp recruitment by turfforming algae and consequences for an Australian kelp community. J Exp Mar Biol Ecol 112:49-60

Kennelly SJ, Underwood AJ (1993) Geographic consistencies of effects of experimental physical disturbance on understorey species in sublittoral kelp forests in central New South Wales. J Exp Mar Biol Ecol 168:35-58

Larkum AWD (1986) A study of growth and primary production in Ecklonia radiata (C. Ag.) J. Agardh (Laminariales) at a sheltered site in Port Jackson, New South Wales. J Exp Mar Biol Ecol 96:177-190

May RM (1977) Thresholds and breakpoints in ecosystems with a multiplicity of stable states. Nature 269:471-477

Melville AJ, Connell SD (2001) Experimental effects of kelp canopies on subtidal coralline algae. Aust Ecol 26:102-108

Peterson CH (1984) Does a rigorous criterion for environmental identity preclude the existence of multiple stable points? Am Nat 124:127-133

Petraitis PS, Dudgeon RS (2004a) Detection of alternative stable states in marine communities. J Exp Mar Biol Ecol 300: 343-371

Petraitis PS, Dudgeon RS (2004b) Do alternate stable community states exist in the Gulf of Maine rocky intertidal zone? Comment. Ecology 1160:1160-1165

Roughgarden J, Diamond J (1986) Overview: the role of species interactions in community ecology. In: Diamond J, Case TJ (eds) Community ecology. Harper and Row, New York, p 333-342

Editorial responsibility: Otto Kinne (Editor-in-Chief), Oldendorf/Luhe, Germany
Ruffin KK (1998) The persistence of anthropogenic turbidity plumes in a shallow water estuary. Estuar Coast Shelf Sci 47:579-592

Scheffer M, Carpenter S, Foley JA, Folke C, Walker B (2001) Catastrophic shifts in ecosystems. Nature 413:591-596

Shears NT, Babcock RC (2002) Marine reserves demonstrate top-down control of community structure on temperate reefs. Oecologia 132:131-142

Shepherd SA, Womersley HBS (1970) The sublittoral ecology of West Island, South Australia. 1. Environmental features and algal ecology. Trans R Soc SA 94:105-137

Tilman D, Lehman C (2001) Human-caused environmental change: impacts on plant diversity and evolution. Proc Natl Acad Sci USA 98:5433-5440

Underwood AJ (1997) Experiments in ecology. Their logical design and interpretation using analysis of variance. Cambridge University Press, Cambridge

Vanderklift MA, Kendrick GA (2004) Variation in abundances of herbivorous invertebrates in temperate subtidal rocky reef habitats. Mar Freshw Res 55:93-103

Vitousek P, Mooney H, Lubchenco J, Melillo J (1997) Human domination of earth's ecosystems. Science 277: 494-499

Wernberg-Møller T (2002) Influence of the canopy-forming kelp Ecklonia radiata (C. Ag.) J. Agardh on associated macroalgal assemblages in southwestern Australia. PhD thesis, University of Western Australia, Crawley

Wilson JFB, Agnew ADQ (1992) Positive-feedback switches in plant communities. Adv Ecol Res 23:263-336

Witman JD, Dayton PK (2001) Rocky subtidal communities. In: Bertness MD, Gaines SD, Hay ME (eds) Marine community ecology. Sinauer Associates, Sunderland, MA, p 339-366

Submitted: April 24, 2003; Accepted: October 26, 2004

Proofs received from author(s): March 3, 2005 